Palimpsesto Vol. 11, № 19 (Julio-diciembre, 2021): 203-212

Universidad de Santiago de Chile, ISSN 0718-5898

Marcelo Claudio Montero

La Casa Espacio de Debate y Cultura

marcelo@lacasaclaypole.org.ar

\title{
Cultura, identidad y resistencia: Elementos para un debate en torno al papel de la gestión cultural en la construcción de la identidad comunitaria*
}

\section{Culture, Identity and Resistance: Elements for a Debate About the Role of Cultural Management in the Construction of Community Identity}

\begin{abstract}
Resumen
El artículo tiene como objetivo reflexionar sobre el potencial de la gestión cultural como herramienta de resistencia a las dinámicas hegemónicas del capitalismo y el papel del arte colectivo como instrumento de construcción de identidad comunitaria.

En primer lugar, se trabajan los conceptos de hegemonía y violencia simbólica y su relación con la cultura; en segundo lugar, se abordan los desafíos y contradicciones en la ampliación de los repertorios artísticos; y finalmente se reflexiona sobre la construcción comunitaria de lo simbólico, para repensar el carácter político de la gestión cultural.
\end{abstract}

Palabras claves: Gestión cultural, hegemonía, violencia simbólica, resistencia, arte comunitario.

\begin{abstract}
This paper aims to reflect about cultural management as a tool to resist the hegemonic dynamics of capitalism, and the role of the community-engaged art as instrument for creating community identity.

At first, the concepts of hegemony and symbolic violence and their relationship with culture are analyzed; then, the challenges and contradictions in the enlargement of artistic repertoires are discussed; finally, this paper focuses on the community construction of the symbolic, to think the political character of cultural management.
\end{abstract}

\footnotetext{
* Artículo correspondiente a la ponencia presentada en el Primer Congreso Internacional de Teatro por la Identidad. Buenos Aires, Argentina, 2021.
} 


\section{Marcelo Claudio Montero}

Keywords: Cultural management, hegemony, symbolic violence, resistance, community art.

iAl diablo con la cultura!

Herbert Read

\section{Hegemonía, violencia simbólica y resistencia}

Si el campo cultural es siempre un espacio de lucha estructurado en términos de relaciones de poder (Bourdieu, 2010), necesariamente se tienen que identificar las tensiones y los espacios de disputa donde el trabajo cultural debe enfocar esa lucha. Actualmente, el mayor desafío para la gestión cultural es reunir las reivindicaciones sociales fragmentadas, para centrarse en la necesidad de volver a pugnar por una causa común; algo que unifique el conjunto de las demandas de diferentes grupos sociales basadas en la igualdad de género, la preservación del ambiente, y otras -evidentemente legítimas y que deben ser permanente visibilizadas por las políticas y acciones culturales-. Hoy, inevitablemente, esta lucha está relacionada con poner en cuestión la lógica del capital. De otra forma, si no se articulan los diversos universos reivindicativos fragmentarios, la hegemonía del sistema que los genera se mantiene intacta.

En gran medida, el desarrollo del capitalismo basa su reproducción en el control de lo simbólico (Vich, 2014) y en el poder generado como ejercicio de la violencia simbólica: "poder de constituir lo dado por la enunciación, de hacer ver y de hacer creer, de confirmar o de transformar la visión del mundo y, por ello, la acción sobre el mundo, por lo tanto el mundo" (Bourdieu, 2007, p. 15).

Las relaciones culturales son una matriz simbólica que definen las prácticas sociales y, de esta manera, terminan constituyéndose en el fundamento de una teoría del poder y de la dominación. La cultura hegemónica es violencia simbólica, justamente porque no existen relaciones de comunicación o conocimiento que no sean relaciones de poder, porque en ellas se realiza el conocimiento de "lo real" (García Canclini, 2004). Esta violencia simbólica se produce "en tanto que imposición, por un poder arbitrario, de una arbitrariedad" (Bourdieu y Passeron, 1977, p. 45). Un poder cuya principal característica es el ocultamiento de su propia naturaleza, es la negación de su construcción a partir de una imposición fundada en relaciones de fuerza de unos sobre otros (Bourdieu y Passeron, 1977). Un proceso de dominación que parece natural y necesario, pero que sabemos, en realidad, histórica y culturalmente construido.

La imposición de esta idea, en tanto violencia simbólica de un poder que legitima significaciones que parecen imposibles de contrarrestar, logra imponer estas significaciones (e imponerlas como legítimas), "disimulando las relaciones de fuerza en que se funda su propia fuerza" (Bourdieu y Passeron, 1977, pág. 44). Se trata de un poder que permite obtener el equivalente de lo que es obtenido por la fuerza física o económica y que se ejerce en su plenitud solo si no es reconocido, es decir, desconocido como poder arbitrario (Bourdieu, 2007). La hegemonía como expresión de una condición de dominación donde la persuasión se sobrepone a la coerción (Guha, 1997).

Para la clase dominante de una sociedad, pensar y expresarse es algo fácil: le basta repetir las ideas que conforman las representaciones dominantes de la sociedad (al fin y 


\section{Marcelo Claudio Montero}

al cabo, como decía Marx, las ideas dominantes de una sociedad son las ideas de su clase dominante). El pensamiento y el discurso de la derecha, apenas variando, alterando y actualizando el stock de imágenes disponibles, reiteran el sentido común que permea en toda la sociedad y que constituye el código inmediato de explicación e interpretación de la realidad, considerado por todos como válido. (De Souza Chaui, 2013, p. 12-13)

Estas condiciones permiten la permanencia hegemónica del capitalismo como sistema universal que, al mismo tiempo, logra una homogeneización sin precedentes del mundo contemporáneo. El capitalismo está aquí para quedarse y ha construido la idea que ya no es viable imaginar nada diferente. Hoy resulta prácticamente imposible cuestionar efectivamente la lógica del capital (Žižek, 1998).

Mientras que a la clase dominante le basta repetir el sentido común producido por ella misma para perpetuarse indefinidamente; plantear una resistencia contracultural, anti hegemónica, implica un enorme esfuerzo sobre la base de practicar el pensamiento crítico, la reflexión sobre el sentido de las acciones sociales y, fundamentalmente, el compromiso con la praxis para la transformación de las condiciones existentes en las que se reproducen y legitiman el ejercicio de la dominación política, la exclusión social y la explotación económica.

Este conjunto de significaciones que se impone como legítimo (el "sentido común" de la clase dominante) es aprehendido por los sujetos en forma previa, como algo ya existente, impuesto y aceptado: es aproblemático porque ya ha pasado por un proceso de naturalización. De esta forma, se convierte en un paradigma de una realidad ordenada, establecida como algo que no puede recibir objeciones. Sus fenómenos se presentan dispuestos de antemano, con pautas que poseen independencia de las personas, que hacen su aparición en un mundo intersubjetivo, que se comparte con otros que también aceptan esta realidad. En definitiva, en la vida cotidiana, en el aquí y ahora, se presenta lo realissimum: las reglas que establecen la vida cotidiana se imponen por sí solas, y debe hacerse un esfuerzo intelectual deliberado y extremadamente complejo, si se desean cuestionar (Berger y Luckmann, 2006).

La hegemonía constituye todo un cuerpo de prácticas y expectativas en relación con la totalidad de la vida: nuestros sentidos y dosis de energía, las percepciones definidas que tenemos de nosotros mismo y de nuestro mundo. Es un vívido sistema de significados y valores -fundamentales y constitutivos- que en la medida en que son experimentados como prácticas parecen confirmarse recíprocamente. Por lo tanto, es un sentido de la realidad para la mayoría de las gentes de la sociedad, un sentido de lo absoluto [...]. Es decir que, en el sentido más firme, es una 'cultura', pero una cultura que debe ser considerada asimismo como la vívida dominación y subordinación de clases particulares. (Williams, 1980, p. 131-132)

Ya no es posible separar el dominio económico de las formas simbólicas, porque actualmente el sistema fundamenta su hegemonía en la producción de imágenes y en la manipulación semiótica: "las imágenes ya no 'representan' a los productos, sino que, antes bien, son estas las que construyen los productos y así generan necesidades y gustos. Hoy todos los objetos del mercado son a la vez signos que seducen" (Žižek, 2003a, citado en Vich, 2014, p. 94 95).

La clase dominante no solo controla los medios de producción material, sino también los medios de producción simbólica (Gramsci, 1977), así como sus mediaciones, ejerciendo el 
predominio de la producción de subjetividad. Se apropia de la producción de símbolos y estéticas como un modo de legitimar su dominación de clase y, en realidad, puede imponerse en el plano económico y reproducir las condiciones de dominación, solo si al mismo tiempo logra la hegemonía del campo cultural. En síntesis "la hegemonía es sinónimo de cultura en el sentido amplio y, sobre todo, de cultura en una sociedad de clases" (De Souza Chaui, 2013, p. 29).

La resistencia cultural no puede buscarse solamente en la generación de nuevas imágenes sobre las identidades sociales, a pesar de que estas apunten a deslegitimar las relaciones de explotación y dominación; es a partir del cuestionamiento del modo de producción de los artefactos estéticos culturales (las obras de arte) y de la propiedad colectiva de los medios de producción artística (o al menos su uso comunitario), dónde se debe buscar la construcción de opciones teórico-prácticas de resistencia al capitalismo neoliberal, para, a partir de allí, producir nuevas subjetividades verdaderamente contrahegemónicas.

El trabajo en cultura debe estar orientado hacia la construcción de una nueva hegemonía, un trabajo para transformar las normas y los hábitos que nos constituyen como sujetos, desmontando y deslegitimando aquello que se presenta como natural y sabemos histórica y socialmente construido. Esta labor debe ser entendida como una opción para visibilizar la centralidad de los significados (es decir, los procesos simbólicos, los objetos culturales) en la estructuración del mundo social y para intentar combatir de las ideologías que lo sustentan (Vich, 2014).

La resistencia cultural implica un enorme trabajo que conlleva varias etapas sucesivas: 1) desmontar el sentido común; 2) desmantelar su apariencia de realidad y verdad natural con la que se presenta; 3) reinterpretar la realidad, revelar sus fundamentos y sus operaciones invisibles para que se pueda comprender y explicar el surgimiento de nuevos cambios; 4) crear un nuevo discurso capaz de expresar una crítica de las ideas y de las prácticas existentes, así como mostrar las ilusiones del sentido común (De Souza Chaui, 2013); y, finalmente, generar una masa crítica que desde la praxis pueda cuestionar las condiciones establecidas que reproducen la dominación y la explotación.

Se deben desarrollar nuevas formas de combate contra la violencia simbólica y las primeras armas están en el pensamiento crítico. "Es a través de la reinvención simbólica como se puede contrarrestar la violencia simbólica” (Peña Collazos, 2009, p. 74)

\section{El papel y las herramientas de la gestión cultural en resistencia}

Tenemos que dotar de sentido político a la gestión cultural. Debemos cuestionar el auge de la técnica y lo técnico, de la corriente dominante que instala la idea central de la gestión cultural como mediación entre el productor de los aparatos estético-culturales y el consumidor; una definición que lleva implícita la visión clásica de emisor-receptor, de público pasivo, y que pone el acento en la circulación de "artefactos culturales elaborados por las industrias culturales (que) son meras mercancías estandarizadas" (Horkheimer y Adorno, 1985, p. 178).

La gestión cultural debe producir actos políticos, profundamente democráticos, contraculturales y anti hegemónicos. El trabajo en cultura tiene que defender la horizontalidad del trabajo colectivo, rompiendo el esquema verticalista de roles y de segmentación impuesto por el mercado (etaria, de género, socioeducativa, etc.). La gestión cultural debe hacer foco en los procesos y no en el producto; un trabajo paciente, que requiere compromiso y perseverancia, que no privilegie los resultados inmediatos, sino las transformaciones a largo plazo. 


\section{Marcelo Claudio Montero}

La gestión de la cultura debe ser el resultado de una construcción colectiva e interdisciplinaria, honesta y fundamentalmente generosa, que desafíe permanentemente los relatos de la posverdad. La posibilidad de imaginarnos y construirnos comunitariamente, dialogando con experiencias, saberes y elementos diversos.

\subsection{La ampliación de los repertorios artísticos: desafíos y contradicciones}

Democratizar y ampliar el acceso a las producciones artístico-culturales aparece como una de las primeras tareas que debe ser encarada con urgencia desde la gestión cultural. Pero es una tarea no exenta de grandes contradicciones. Al fin y al cabo ¿qué se debe democratizar?

Por un lado, se trata de resistir la frivolidad que promueven las industrias culturales y los medios de comunicación masivos, a partir de la ampliación del abanico de la oferta cultural, y de la circulación de nuevas producciones que fomenten la reflexión frente a la permanente presión de la industria cultural por lo pasatista y frívolo; pues la falta de acceso a expresiones artísticas alternativas, no masivas, en las clases populares, en las poblaciones y barrios de periferia, funciona finalmente como un dispositivo de discriminación simbólica que condiciona la formación de hábitos, alimenta la segregación cultural y define los gustos existentes. Una manera de elegir con que elementos se construye la propia identidad, que no es verdaderamente elegida. Pero, por otro lado, para democratizar el acceso a los bienes culturales no basta ampliar el acceso, la circulación y asegurar la gratuidad de la oferta de productos artísticos de pretendido alto valor estético o "socialmente designados como admirables" (Durán y Jaroslavsky, 2012), porque en realidad solo podrán acceder a su disfrute aquellos que posean los medios simbólicos para hacerlos suyos (García Canclini, 2004). La sociedad capitalista organiza permanentemente la distribución desigual de los bienes, tanto los materiales como los simbólicos, y la principal diferenciación se establece, más que en los bienes artísticos y culturales en si mismos, en la forma que las clases los apropian (García Canclini, 2004).

Si bien a partir de la cultura de masas y de la industria cultural, las fronteras entre alta cultural y baja cultura se diluyen (Peters, 2021) y pese a que ya no es lícito hablar de "la cultura" como un categoría absoluta y universal, sino de múltiples formas de aprehender el mundo; perdura la valoración y jerarquización de lo estético como propiedad de clase. El énfasis en el disfrute de la experiencia estética, despojada de las necesidades y de las urgencias prácticas, presupone la bondad de apreciar el arte independientemente de su contenido y su función. El arte por el arte en sí mismo -que Canclini (2004) denomina arte incestuoso- fija un modo "correcto" de apreciar lo artístico, supuestamente desvinculado de la existencia material. El goce artístico de las clases dominantes requiere desentenderse de la vida cotidiana, oponerse a ella. Compartir esta disposición para el goce estético, implica manifestar una posición de privilegio en el espacio social: "el modo burgués de producir y consumir el arte organiza simbólicamente las diferencias entre las clases" (GARCÍA CANCLINI, 2004, p. 64). Implica "mirar el mundo como las clases dominantes quieren que se mire [...]. Una postura pasiva del espectador, que corresponde a la pasividad de la mayoría del pueblo en la vida real" (BRECHT, 1973, p. 185).

Creer que democratizar el acceso a los bienes simbólicos es universalizar el acceso igualitario de lo que está socialmente designado como admirable o consagrado, es decir, privilegiar el acceso de las clases populares a la producción simbólica de las clases dominantes, es legitimar la violencia simbólica que está implícita en esa designación; pues la designación de lo bello solo puede ser realizada por quienes pertenecen a la clase que cuenta con el capital 
cultural necesario para decodificar y definir la belleza en los cánones propios de su campo cultural. Por otra parte, cabe preguntarse si puede implantarse artificialmente un hábitus específico de un campo sin contar con el conjunto del capital propio de ese campo (el social, el económico, el simbólico). ¿Es posible apropiar y reproducir la competencia cultural, sin el acceso al capital del campo que detenta el monopolio de dicha competencia?

A fin de cuentas, privilegiar el goce puramente estético como una experiencia en si misma, alejada de las necesidades de las clases populares, es anular sus aptitudes críticas:

Nos referimos a la toma de posición del espectador; es la emancipación de este lo que nos interesa; es más, lo que nos preocupa es su 'emancipación' de la vivencia artística total [...]. (El arte) debe dejar el camino libre a la actitud crítica del espectador [...]. La crítica del espectador se manifiesta en dos sentidos. Por una parte se refiere a la representación del actor (¿es acertada la interpretación?) y, por la otra, al mundo que se representa (¿debe quedar así?) [...]. La situación cambia cuando lo que se observa no es la representación artística del mundo, sino el mundo mismo, un mundo al que se debe criticar, discutir, considerar con una cierta perspectiva. (Brecht, 1973, p. 196-198)

\subsection{Lo comunitario: el camino de la resistencia}

Para entablar una lucha contra los cánones que hegemonizan las representaciones artísticas, que han impuesto sentidos estéticos (y obviamente políticos), que instalan la idea del desarrollo de la libre creatividad individual, es indispensable abrir espacios de participación popular genuina, para, de esa manera, producir nuevas representaciones, como una tarea indispensable de la gestión en cultura.

Frente al sentimiento generalizado de escepticismo y de falta de certeza sobre el presente, generador de una poderosa fuerza individualizadora que desmantela las formas de solidaridad y conducta colectiva (De La Garza, 2001); es imperioso desmontar las prácticas sociales sumergidas en una dinámica de descolectivización social (Bauman, 2001). Desde la gestión de la cultura, la lucha contra la insolidaridad debe recorrerse por el camino lo colectivo: el proceso de interacción creativa de elementos de una comunidad, que encuentran en las artes (principalmente en el teatro, el cine o el muralismo) una posibilidad colectiva de expresión, que a pesar de ser, en última instancia, una acción artística, su objetivo es superador de aquel que se concibe solamente como un producto estético. La potencialidad del arte comunitario es principalmente el rescate del quehacer colectivo, interdisciplinario y colaborativo de la producción, priorizando, y esto es esencial, no el resultado artístico, sino el proceso: no un producto final, sino la dinámica de producción que genera su quehacer.

La burguesía ya sabe como es el mundo, su mundo, y puede presentar imágenes de ese mundo completo, terminado. La burguesía presenta el espectáculo. En cambio el proletariado y las clases explotadas no saben todavía como será su mundo; consecuentemente su teatro será el ensayo, y no el espectáculo acabado. (Boal, 1980, p. 42)

Democratizar el acceso a la cultura es democratizar la producción simbólica en la comunidad. Asegurar, por un lado, el uso colectivo de los medios de producción y, por otro, el 
acceso a la formación y al dominio de la técnica en los sectores populares (mediante talleres, colectivos populares de producción, grupos de intervención, etc.), como un instrumento, no para el goce estético de lo "socialmente designado como admirable", sino para adquirir y desarrollar herramientas expresivas y de reflexión sobre la propia realidad cotidiana, a partir de las experiencias artísticas, cuestionando los modos de producción individualistas, jerárquicos y mercantiles.

Lo colectivo, lo comunitario, debe contribuir a la superación de estos conceptos y prácticas minoritarias; debe dejar de perseguir la "calidad artística" de la obra, colocar en un plano secundario la búsqueda de la perfección estética, porque un arte perfecto - técnica y artísticamente logrado - es casi siempre reaccionario (García Espinoza, 1970).

La actual perspectiva de la cultura artística no es más la posibilidad de que todos tengan el gusto de unos cuantos, sino la de que todos puedan ser creadores de cultura artística. El arte siempre ha sido una necesidad de todos. Lo que no ha sido una posibilidad de todos en condiciones de igualdad [...]. La producción desarrollada por una minoría para satisfacer la demanda de una masa reducida al único papel de espectadora y consumidora. (García Espinoza, 1970, p. 40)

Poner el foco en el proceso y en el modo de producción, y no en los objetos artísticos, en una sociedad donde todo tiende a convertirse en mercancía, donde todo es homogéneo, todo es igualable y susceptible de ser valorado en términos de dinero (Margulis, 2006), opera finalmente como una forma de desfetichización: una contra reificación, una resistencia a cuantificar y medir el trabajo y a cosificar el sujeto y las relaciones sociales de producción artística. No existe una valoración mercantil posible en el arte comunitario: el sujeto se reconoce en lo que produce tanto como en aquellos con quienes produce. Los lenguajes, las prácticas y los procesos de producción y exhibición, encuentran raíz y destino en "lo común" (Molfetta, 2017, p. 22). Es la comunidad la que retroalimenta el proceso y es, al mismo tiempo, quien recibe el resultado de ese proceso en una "recepción circular" (Molfetta, 2017, p. 84), es decir, protagonizada por los mismos realizadores y su comunidad. Esto permite su auto reafirmación como grupo social y, a largo plazo, la construcción de su propia identidad comunitaria.

La resistencia directa al centro de las formas capitalistas de la mercantilización, fetichización de la mercancía, de la reificación o cosificación, es fundamental para pensar la producción simbólica más allá del capital.

\subsection{La muerte del artista}

Como dicho en el punto anterior, lo central en la producción comunitaria es lo colectivo y, de acuerdo a lo definido por Molfetta (2017), específicamente, la lucha por un arte sin autor.

Roland Barthes (1994) desarrolló su idea sobre la muerte del autor a partir de la obra literaria. Dado que es la obra literaria quien media directamente entre autor y lector, podemos decir que la muerte del autor para Barthes es en realidad la muerte del artista: la muerte de la autoridad, de cualquier "tiranía" que opaque, obstaculice y condicione la experiencia artística.

Una vez demolido el pedestal, el artista pierde su papel protagónico y "el yo da paso al nosotros y, la obra vuelve a los dominios de la colectividad" (ARCOS-PALMA, 2007, p. 39). La muerte del autor, la muerte del artista es en verdad un cambio de autoridad: se da en el pasaje del 
individuo al colectivo. Eliminar la propiedad privada de la obra, "eliminar la propiedad privada de los personajes" (Boal, 1980, p. 42) es condición sine qua non para el arte colectivo. La apropiación colectiva del arte permite resistir a la idea de la concentración exclusiva del talento artístico en algunos individuos mientras está relegada de la masa social; y permite soñar con una sociedad en la que "ya no habrá pintores, sino, cuando mucho, hombres que, entre otras cosas, practiquen la pintura” (Marx y Engels, 2007, p. 381).

He dicho: al diablo con la cultura; y debería agregar: al diablo con el artista [...]. En una sociedad natural no existirán esos seres preciosos o privilegiados que conocemos con el nombre de artistas; sólo habrá trabajadores. O si prefieren la expresión, más paradójica, con que Gill se refería a la misma verdad, diré: en una sociedad natural no existirán esas criaturas despreciadas y desheredadas a las que llamamos trabajadores; sólo habrá artistas. El artista no constituye una clase especial de hombre; pero todo hombre es una clase especial de artista. (Read, 2011, p. 33)

\section{Conclusión}

Pensar (y practicar) la cultura más allá de los objetos simbólicos, como el conjunto de hábitos, normas, sentidos comunes y estereotipos que nos socializan y que reproducimos, hará de la gestión de la cultura una herramienta para cuestionar estos hábitos, desmenuzarlos $\mathrm{y}$, sobre todo desnaturalizarlos, para emprender la tarea de pensar nuevas realidades posibles. La cultura no es solo el reflejo del mundo, sino también un arma de potencial transformación.

Frente al predominio de lo estético y lo técnico, debemos privilegiar lo político en la gestión cultural. La experiencia estética debe servir para aprehender el mundo desde la percepción y los sentidos, pero principalmente, debe ser una herramienta para pensar y entender el mundo, y, sobre todo, una oportunidad para transformarlo. Sentir el mundo, pensar el mundo y actuar para transformarlo: sobrepasar la bidimensionalidad de seres sentipensantes (Fals Borda, 2002a, p. 25B), para pasar a ser seres tridimensionales a partir de las posibilidades de lo simbólico: seres sentipensactuantes. Desde el arte, debe rebelarse a la comunidad "el mundo como un mundo que está a su disposición y a disposición de su intervención" (Brecht, 1973, p. 185).

Hoy, nuestra identidad cultural debe ser la cultura de la resistencia, comunitaria y colectiva. La democratización de lo simbólico como dispositivo de construcción de comunidad. La búsqueda de un arte imperfecto, colectivo. La resistencia activa para la construcción de nuevos imaginarios y nuevas imágenes. Como afirma Victor Vich (2014, p. 98), debemos "entender la cultura como un nuevo poder y, sobre todo, comenzar a tomar el poder desde la cultura". 


\section{Bibliografía}

Arcos-Palma, R. (2007). De la muerte del autor a la muerte del artista: reflexión crítica para un debate en torno a la figura del autor. Calle 14 revista de investigación en el campo del arte, 1(1), 34-44.

Barthes, R. (1994): La muerte del autor. En: BARTHES, R.: El susurro del lenguaje: más allá de la palabra y de la escritura. Barcelona: Paidós.

Bauman, Z (2001). Modenidade Líquida. Río de Janeiro: Zahar.

Berger, P. L. y Luckmann, T. (2006). La Construcción Social de la Realidad. Buenos Aires: Amorrortu.

Boal, A (1980): Teatro del oprimido 1: teoría y práctica. México: Nueva Imagen

Bourdieu, P. (2007): O poder simbólico. Rio de Janeiro: Bertrand Brasil.

Bourdieu, P. \& Passeron, J. (1977): La reproducción: elementos para la teoría del sistema de enseñanza. Barcelona: Laia.

Brecht, B. (1973): Escritos sobre teatro. Tomo 1. Buenos Aires: Nueva Visión. . (1976): Escritos sobre teatro. Tomo 2. Buenos Aires: Nueva Visión.

De La Garza, E. (2001). Problemas clásicos y actuales de la crisis del trabajo. En: De La Garza, E. \& Neffa, J. (comps.), El trabajo del Futuro. El futuro del trabajo (pp. 11-31). Buenos Aires: CLACSO.

De Souza Chaui, M. (2013): Ciudadanía cultural: el derecho a la cultura. Buenos Aires: RGC.

Duran, A. \& Jaroslavsky, S. (2012): Cómo formar espectadores en la era digital: una experiencia desde el ámbito del Estado con adolescentes de las escuelas de la ciudad de Buenos Aires y el teatro independiente. Buenos Aires: Leviatán.

Fals Borda, O. (2002): Historia doble de la costa 2: resistencia en el San Jorge. Bogotá: Universidad Nacional de Colombia - El Áncora Editores.

García Canclini, N. (2004): Diferentes, desiguales, desconectados: mapas de la interculturalidad. Barcelona: Gedisa.

García Espinoza, J. (1970): Por un cine imperfecto. Hablemos de cine, (55/56) 37-42.

Gramsci, A. (1977): Antología. México: Siglo XXI.

Guha, R. (1997). Dominance without Hegemony: history and power in colonial India. Londres: Harvard University Press.

Horkheimer, M. \& Adorno, T. (1985): La industria cultural. En: Bell, D., Mac Donald, D., Shils, E., Adorno, T., Horkheimer, M. \& Lazarsfed, P.: Industria cultural y sociedad de masas. Caracas: Monte Ávila.

Margulis, M. (2009): Sociología de la cultura: conceptos y problemas. Buenos Aires: Biblos. . (2006): Ideología, fetichismo de la mercancía y reificación. Estudios Sociológicos, XXIV (70), 31-64.

Marx, K. \& Engels, F. (2007): A ideologia alemã. São Paulo, Brasil: Boitempo Editorial.

Molfetta, A. (comp) (2017): Cine comunitario argentino: mapeos, experiencias y ensayos 20052015. CABA, Argentina: Teseo.

Peña Collazos, W. (2009): La violencia simbólica como reproducción biopolítica del poder. Revista Latinoamericana de Bioética, 9 (2) pp. 62-75. 
Peters, T. (2021): Sociología(s) del arte y de las políticas culturales. Buenos Aires: RGC.

Read, H. (2011): Al diablo con la cultura. Buenos Aires: Godot.

Vich, V. (2014): Desculturizar la cultura: la gestión cultural como forma de acción política. Buenos Aires: Siglo XXI Editores.

Williams, R (1980): Marxismo y literatura. Barcelona, España: Península.

Žižek, S. (1998): Multiculturalismo o la lógica cultural del capitalismo multinacional. En: Jameson, F. \& Žižek, S.: Estudios Culturales: reflexiones sobre el multiculturalismo. Buenos Aires: Paidos. 